\title{
Acute severe asthma: Part 1. Pathophysiology and clinical assessment
}

\author{
ROBERT G. GARMON, DO \\ RICHARD B. ZEMENICK, DO
}

Asthma manifests itself in a two-phase reaction. An early phase, causing bronchial muscle contraction, occurs within minutes after an antigenic stimulus. Within 6 to 18 hours, a late asthmatic response begins. This response is associated with cellular infiltration of the bronchial submucosa by eosinophils, neutrophils, and lymphocytes. The late asthmatic response is most effectively reversed by the use of corticosteroids. Predicting patient outcome solely on the basis of either physical findings, or pulmonary function tests, or historical events is frequently inadequate. Historical events, clinical assessments, and laboratory and pulmonary function measurements are best used in a complementary and integrated fashion to determine appropriate disposition of the acutely asthmatic patient.

(Key words: Bronchial asthma, bronchospasm, status asthmaticus, pulmonary function tests)

From Texas College of Osteopathic Medicine (TCOM), Fort Worth, where at the time this paper was written, Dr Garmon was associate professor of medicine, Department of Medicine, and Dr Zemenick was associate professor, Division of Emergency Medicine. Currently, Dr Garmon is clinical associate professor in the Department of Internal Medicine, TCOM, and medical director of the Pulmonary Function Laboratory and Respiratory Therapy Departments at Campbell Memorial Hospital, Weatherford, Tex. Dr Zemenick is now assistant attending staff, St Paul Medical Center, Dallas, Tex.

Reprint requests to Robert G. Garmon, DO, $716 \mathrm{E}$ Anderson, Suite 103, Weatherford, TX 76086.
Mortality from bronchial asthma has increased in children and adults in the United States and other western nations during the past 10 years, despite the availability and use of effective pharmacologic agents for the control of the disease. Most of the increased deaths attributable to asthma have occurred in patients 45 years of age or older. ${ }^{1}$ The mortality rate among black children and adults has been at least twice as high as that for whites. ${ }^{2}$ During much of the period of increasing deaths caused by asthma, US hospitalizations for treatment of asthma also increased by as much as $50 \%$ among adults and $200 \%$ among children. ${ }^{3}$ Approximately $50 \%$ of deaths from asthma in this country occur in hospitals. These trends in deaths caused by asthma come at a time when deaths from respiratory diseases other than asthma are gradually decreasing. ${ }^{4}$

The Asthma Mortality Task Force ${ }^{5}$ concluded in 1986 that "fatalities in patients with asthma are related to withholding corticosteroid or to inadequate steroid dosage in patients with severe asthma." The task force recommended an educational campaign among physicians and patients, emphasizing the rationale for using corticosteroids. This article reviews the pathophysiologic aspects of the response to asthma triggers. The assessment of the severity of acute asthma is discussed.

\section{Pathophysiology of asthma}

The increased bronchial responsiveness in asthma manifests itself in a two-phase reac- 
tion. ${ }^{6}$ The early asthmatic reaction characteristically involves the release of mediators, resulting in bronchial smooth muscle contraction and peribronchial vascular leakage with edema. When limited to a single brief stimulus, this early response begins within minutes, causing a significant decrease in expiratory airflow as measured by reduction of forced expiratory volume in 1 second $\left(\mathrm{FEV}_{1}\right)$. The early asthmatic response resolves spontaneously within 1 or 2 hours, or it may be aborted by administration of an aerosol $\beta$-adrenergic receptor agonist. Within 6 to 18 hours after an inhaled antigen stimulus, a late asthmatic response begins and a second decrease in $\mathrm{FEV}_{1}$ occurs. This late response corresponds with cellular infiltration of the bronchial submucosa and mucosa by eosinophils, neutrophils, and lymphocytes. Mucosal edema is increased, and submucosal basement membrane swelling also occurs. ${ }^{7,8}$

The early asthmatic response, bronchospasm, is relieved most quickly by inhaled $\beta$ adrenergic receptor agonist bronchodilators, whereas the late asthmatic response, that is, eosinophilic inflammation, is most powerfully relieved by systemic corticosteroids; somewhat less potently by aerosol corticosteroids. ${ }^{9-12}$ Pretreatment of the patient with $\beta$-agonists or theophylline can block the immediate or early response. Pretreatment with cromolyn sodium or sustained treatment with aerosol corticosteroids can prevent or attenuate both the early and late asthmatic responses. ${ }^{9}$ Use of these medications does not cure asthma, but in some situations may help to make the asthmatic patient's airways less sensitive to irritants or other stimuli.

With persistent, effective therapy of several months' duration, the patchily denuded basement membrane of the airway, with its exposed vagal nerve endings, may be covered by a new and intact bronchial epithelium. The intact epithelium of ciliated columnar cells then acts as a protective barrier for the underlying basement membrane. In a significant number of adolescent and young adult asthmatic patients, when this sequence of healing events occurs, the asthma may become asymptomatic. At this point, if results of pulmonary function studies remain normal for a month or two, the asthma may be said to be in remission. Pharmacologic treatment may be substantially reduced or discontinued with little risk of recurrence for months or occasionally years in some instances.

Protracted asthma unresponsive to outpatient therapy, that is, status asthmaticus, signifies severe airway inflammation with mucous plugging in addition to bronchospasm. The mucous plugging is the major cause of maldistribution of ventilation and hypoxemia that sometimes result in death. The inflammatory process with edema and airway plugging also causes severe air trapping within the lungs with ensuing rupture of alveoli and wicking of air down the bronchial sheath through the hilum into the mediastinum. From the mediastinum, air may be forced into the subcutaneous tissues of the neck and chest wall to produce subcutaneous emphysema, or the air may dissect into the pleural space to result in a pneumothorax. Usually, tension is generated from such air trapping because of mucous plugging and bronchial edema and can lead to catastrophic deterioration. In a recent retrospective review, more than one third of asthmatic patients seen in cardiac arrest had a pneumothorax. ${ }^{13}$

\section{Assessment of severity}

The extreme inflammatory changes involved in an acute asthmatic attack usually do not develop in a few hours or even a few days. Commonly, the symptoms, most notably cough, begin several days to several weeks before the emergent episode. Since cough without associated wheezing usually is not ascribed to asthma by most patients and by many physicians, the bronchial inflammation producing the cough continues to increase while the patient-and sometimes the physician-inappropriately medicates the symptom with expectorants, decongestants, or sometimes even cough suppressants. It must be emphasized that a cough persisting more than a few hours in a previously diagnosed asthmatic patient should be viewed as a harbinger of a potentially severe or life-threatening attack. In one study, $12 \%$ of patients coming to the emergency room

(continued on page 223) 
When diet and exercise alone are not enough...
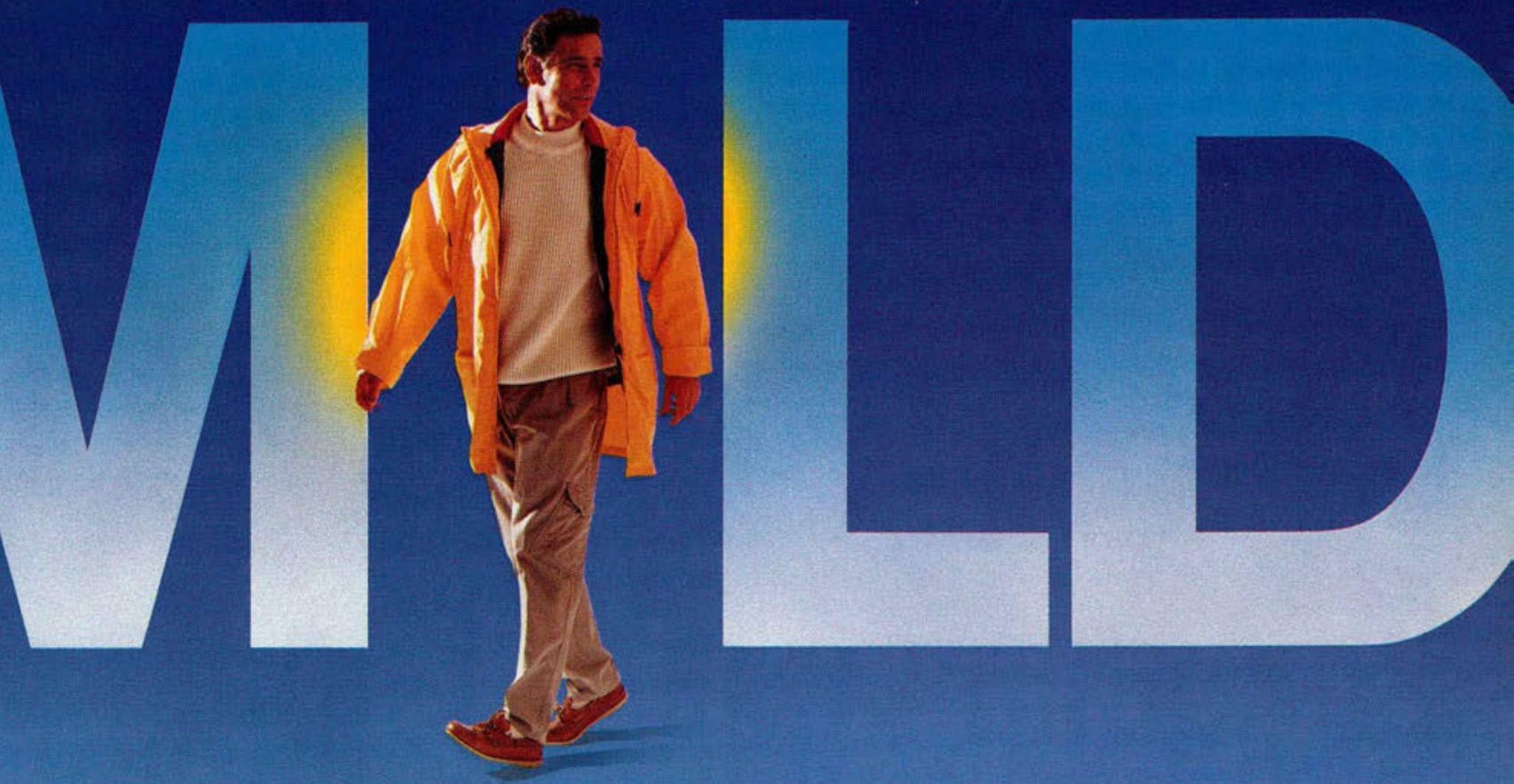

\title{
A MILD START IN MILD HYPERTENSION
}

\author{
- SINGLE-AGENT EFFICACY \\ - ONCE-DAILY STARTING DOSE \\ -EXCELLENT TOLERABILITY ${ }^{1 t}$ \\ - NO ADVERSE EFFECTS ON LIPID AND GLUCOSE \\ LEVELS $S^{2.4}$ OR ON RENAL FUNCTION ${ }^{5}$
}

The recommended starting dose for Calan SR is $180 \mathrm{mg}$ once daily. Dose titration will be required in some patients to achieve blood pressure control

A lower inital starting dostge of $120 \mathrm{mg}$ day may be warranted in some patients (eg, the elderly, patients of smail staturel Dosapes above $240 \mathrm{mig}$ daik should be administeres in divided doses calan SR should be administered with food t Constipation. which is easiv mansged in most pattents, is thie most commonily reported side effect of Calan SR

Yeranamil should be administered cautiousiv to patients with moaredronglefinction

Please see next page of this advertisement for references and brief summary of prescribing information
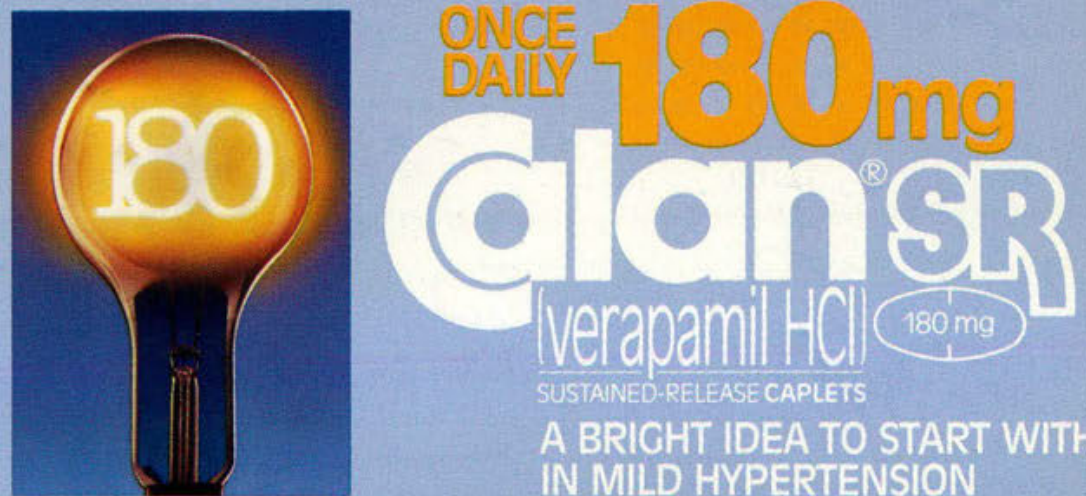

A BRICHT IDEA TO START WITH IN MILD HYPERTENSION 


\section{When diet and exercise alone are not enough... A MILD START IN MILD HYPERTENSION}
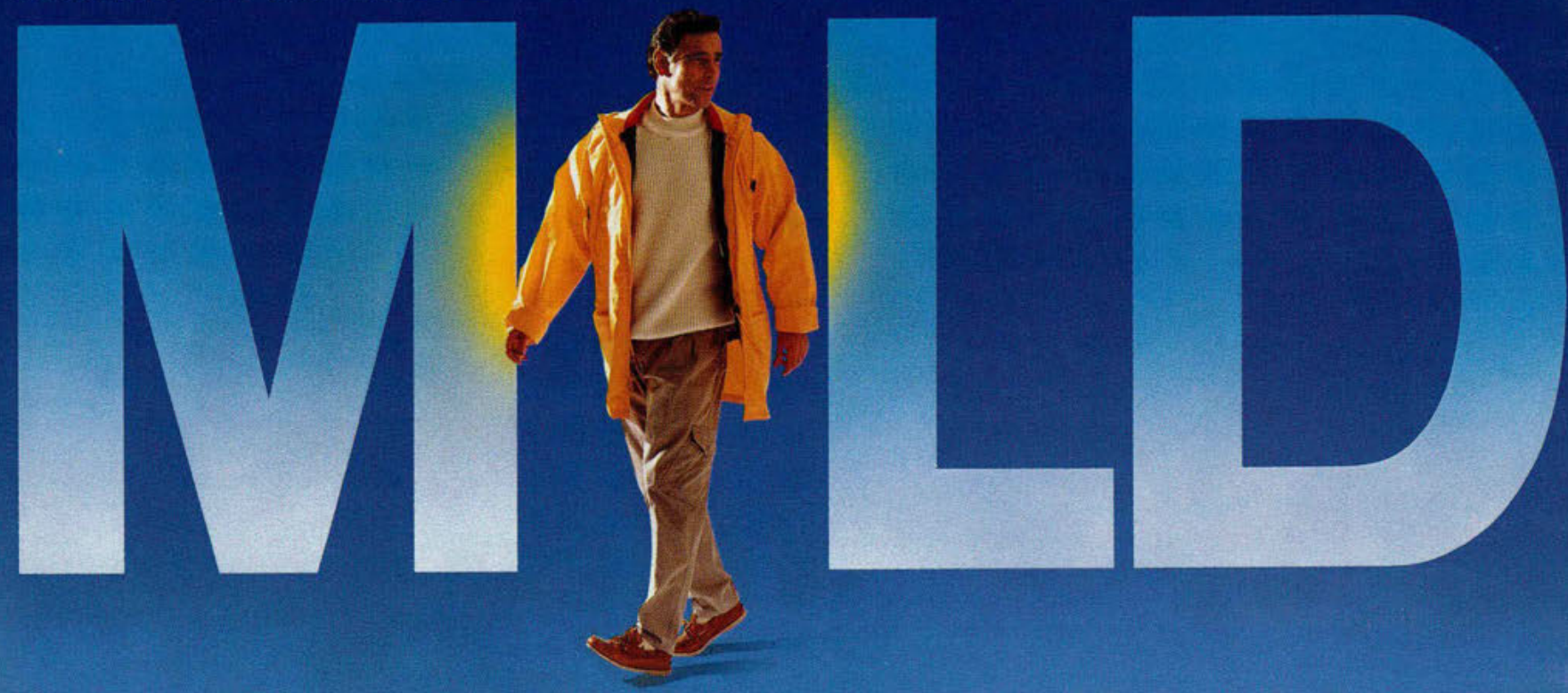

- Single-agent efficacy

- Low incidence of side effects

- Once-daily $180 \mathrm{mg}$ - the recommended starting dose for Calan SR

- Scored caplet provides easy titration

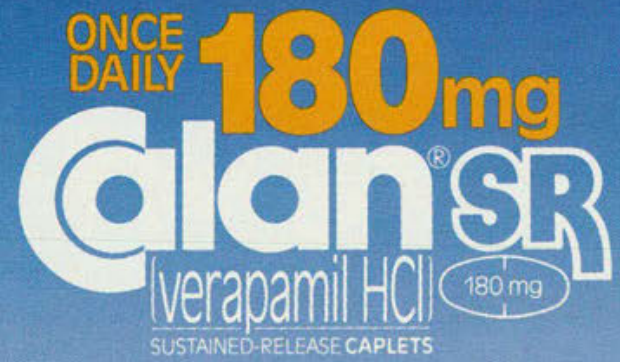

References:

1. Data on file, G.D. Searle \& CO. 2. Midtbø KA. Effects of Iong-term verapamil therapy on serum lipids and other metabolic parameters. Am J Cardio 1990:66:131-15I. 3. Krone W. Nagele H. Effects of antihypertensives on plasma lipids and lipoprotein metabolism. Am Heart J. 1988:116:1729:1734 4. Cruickshank JK, Anderson NMCF. Wadsworth J, et al. Treating hypertensive diabetics: a comparison of verapamil and metoprolol in black and white patients. J Cardiovasc Pharmacol. 1987; 10 (suppl 10):\$85-\$86.5. Schmieder RE, Messerli FH. Garavaglia GE, et al. Cardiovascular effects of verapamil in patients with essential hypertension. Circulation. 1987:75:1030-1036

\section{BRIEF SUMMARY}

Contraindications: Severe LV dysfunction (see Warnings), hypotension (systolic pressure $<90 \mathrm{~mm} \mathrm{Ha}$ ) or cardiogenic shock, sick sinus syndrome (if no pacemaker is present), 2nd-or 3rd-degree AV block (if no pacemaker is present), atrial flutter/fibrillation with an accessory bypass tract (eg, WPW or LGL syndromes), hypersensitivity to verapamil.

Warnings: Verapamil should be avoided in patients with severe LV dysfunction (eg, ejection fraction $<30 \%$ ) or moderate to severe symptoms of cardiac failure and in patients with any degree of ventricular dysfunction if they are receiving a beta-blocker. Control milder heart failure with optimum digitalization and/or diuretics before Calan SR is used. Verapamil may occasionally produce hypotension. Elevations of liver enzymes have been reported. Several cases have been demonstrated to be produced by verapamil. Periodic monitoring of liver function in patients on verapamil is prudent. Some patients with paroxysmal and/or chronic atrial flutter/fibrillation and an accessory AV pathway (eg, WPW or LGL syndromes) have developed an increased antegrade conduction across the accessory pathway bypassing the AV node, producing a very rapid ventricular response or ventricular fibrillation after receiving I.V. verapamil (or digitalis). Because of this risk, oral verapamil is contraindicated in such patients. AV block may occur (2nd-and 3 rd-degree, $0.8 \%$ ). Development of marked 1 st-degree block or progression to 2 nd- or 3 rddegree block requires reduction in dosage or, rarely, discontinuation and institution of appropriate therapy. Sinus bradycardia, 2nd-degree AV block, sinus arrest, pulmonary edema and/or severe hypotension were seen in some critically ill patients with hypertrophic cardiomyopathy who were treated with verapamil.

Precautions: Verapamil should be given cautiously to patients with impaired hepatic function (in severe dysfunction use about $30 \%$ of the normal dose) or impaired renal function, and patients should be monitored for abnormal prolongation of the PR interval or other signs of overdosage. Verapamil may decrease neuromuscular transmission in patients with Duchenne's muscular dystrophy and may prolong recovery from the neuromuscular blocking agent vecuron jum. It may be necessary to decrease verapamil dosage in patients with attenuated neuromuscular transmission. Combined therapy with beta-adrenergic blockers and verapamil may result in additive negative effects on heart rate, atrioventricular conduction and/or cardiac contractility: there have been reports of excessive bradycardia and AV block, including complete heart block. The risks of such combined therapy may outweigh the benefits. The combination should be used only with caution and close monitoring. Decreased metoprolol and propranolol clearance may occur when either drug is administered concomitantly with verapamil. A variable effect has been seen with combined use of atenolol. Chronic verapamil treatment can increase serum digoxin levels by $50 \%$ to $75 \%$ during the first week of therapy, which can result in digitalis toxicity. In patients with hepatic cirrhosis, verapamil may reduce total body clearance and extrarenal clearance of digitoxin. The digoxin dose should be reduced when verapamil is given, and the patient carefully monitored. Verapamil will usually have an additive effect in patients

\section{Calan SR 180-mg caplets are scored for easy titration.}

receiving blood-pressure-lowering agents. Disopyramide should not be given within 48 hours before or 24 hours after verapamil administration. Concomitant use of flecainide and verapamil may have additive effects on myocardial contractility, AV conduction, and repolarization. Combined verapamil and quinidine therapy in patients with hypertrophic cardiomyopathy should be avoided, since significant hypotension may result. Concomitant use of lithium and verapamil may result in a lowering of serum lithium levels or increased sensitivity to lithium. Patients receiving both drugs must be monitored carefully. Verapamil may increase carbamazepine concentrations during combined use. Rifampin may reduce verapamil bioavailability. Phenobarbital may increase verapamil clearance. Verapamil may increase serum levels of cyclosporin. Verapamil mav inhibit the clearance and increase the plasma levels of theophylline. Concomitant use of inhalation anesthetics and calcium antagonists needs careful titration to avoid excessive cardiovascular depression. Verapamil may potentiate the activity of neuromuscular blocking agents (curare-like and depolarizing); dosage reduction may be required. There was no evidence of a carcinogenic potential of verapamil administered to rats for 2 years. A study in rats did not suggest a tumorigenic potential, and verapamil was not mutagenic in the Ames test. Pregnancy Category C. There are no adequate and well-controlled studies in pregnant women. This drug should be used during pregnancy, labor, and delivery only if clearly needed. Verapamil is excreted in breast milk; therefore, nursing should be discontinued during verapamil use.

Adverse Reactions: Constipation (7.3\%), dizziness $(3.3 \%)$, nausea $(2.7 \%)$, hypotension $(2.5 \%)$ headache $(2.2 \%)$, edema $(1.9 \%)$, CHF, pulmonary edema $(1.8 \%)$, fatigue $(1.7 \%)$, dyspnea $(1.4 \%)$, bradycardia: $H R<50 /$ min $(1.4 \%)$, AV block: total $1^{\circ}, 2^{\circ}, 3^{\circ}(1.2 \%), 2^{\circ}$ and $\left.3^{\circ} 10.8 \%\right)$, rash $(1.2 \%)$, flushing $(0.6 \%)$, elevated liver enzymes, reversible non-obstructive paralytic ileus. The following reactions, reported in $1.0 \%$ or less of patients, occurred under conditions where a causal relationship is uncertain: angina pectoris, atrioventricular dissociation, chest pain, claudication, myocardial infarction, palpitations, purpura (vasculitis), syncope, diarrhea, dry mouth gastrointestinal distress, gingival hyperplasia, ecchymosis or bruising, cerebrovascular accident confusion, equilibrium disorders, insomnia, muscle cramps, paresthesia, psychotic symptoms, shakiness, somnolence, arthralgia and rash, exanthema, hair loss, hyperkeratosis, macules, sweating, urticaria, Stevens-Johnson syndrome, erythema multiforme, blurred vision, gynecomastia, galactorrhea/hyperprolactinemia, increased urination, spotty menstruation, impotence.

$4 / 11 / 91 \cdot P 91 C A 6277 \mathrm{~V}$

Address medical inquiries to:

G.D. Searle \& Co.

Medical \& Scientific

Information Departmen

4901 Searle Parkwa
Skokie, IL 60077 
with an acute asthmatic episode denied having dyspnea; however, all reported coughing. ${ }^{14}$ Wheezing or dyspnea (or both) usually indicates a more advanced stage of asthma with severe inflammation, edema, and mucous plugging. This stage may be reached by gradual progression over several days or weeks from the cough stage, or it may occur over a few hours after a concentrated exposure to antigens or irritants. However, systemic anaphylaxis should be considered in patients having a sudden onset of difficulty breathing or wheezing.

Assessment of the degree of ventilatory impairment begins with simple observations. Speech broken into two- or three-word phrases because of dyspnea generally indicates significant alteration in pulmonary mechanics. Respiratory rates of more than 25 breaths per minute that do not slow to between 12 to 20 breaths per minute shortly after treatment are reason for concern and closer monitoring of pulmonary function. A heart rate of more than 110 beats per minute or systolic and diastolic hypertension are signs of disturbed pulmonary mechanics and hypoxemia.

Diaphoresis, sternocleidomastoid muscle contraction, and paradoxical pulses are associated with severe airway obstruction..$^{15-17}$ Diaphoresis may be more specific for severe airflow obstruction than accessory muscle use or paradoxical pulse. The accessory muscle use and paradoxical pulse tend to occur together. ${ }^{15}$ Sternocleidomastoid muscle contraction and paradoxical pulse have been noted to be absent in $52 \%$ of patients with an $\mathrm{FEV}_{1}<1 \mathrm{~L}^{16}$ Inappropriate or paradoxical inward motion of the lower anterior chest wall and upper abdomen during inspiration is an indication of diaphragmatic overload. ${ }^{18}$ The efficiency of diaphragmatic contraction is reduced because it is displaced downward by the overdistended lungs, and the contractile force required during inhalation is increased because of inspiratory airflow obstruction and air trapping. Particularly ominous are signs of confusion, agitation, or stupor. Mechanically assisted ventilation is often needed at this point to prevent bradypnea, apnea, and death.

Objective measurements of pulmonary me-

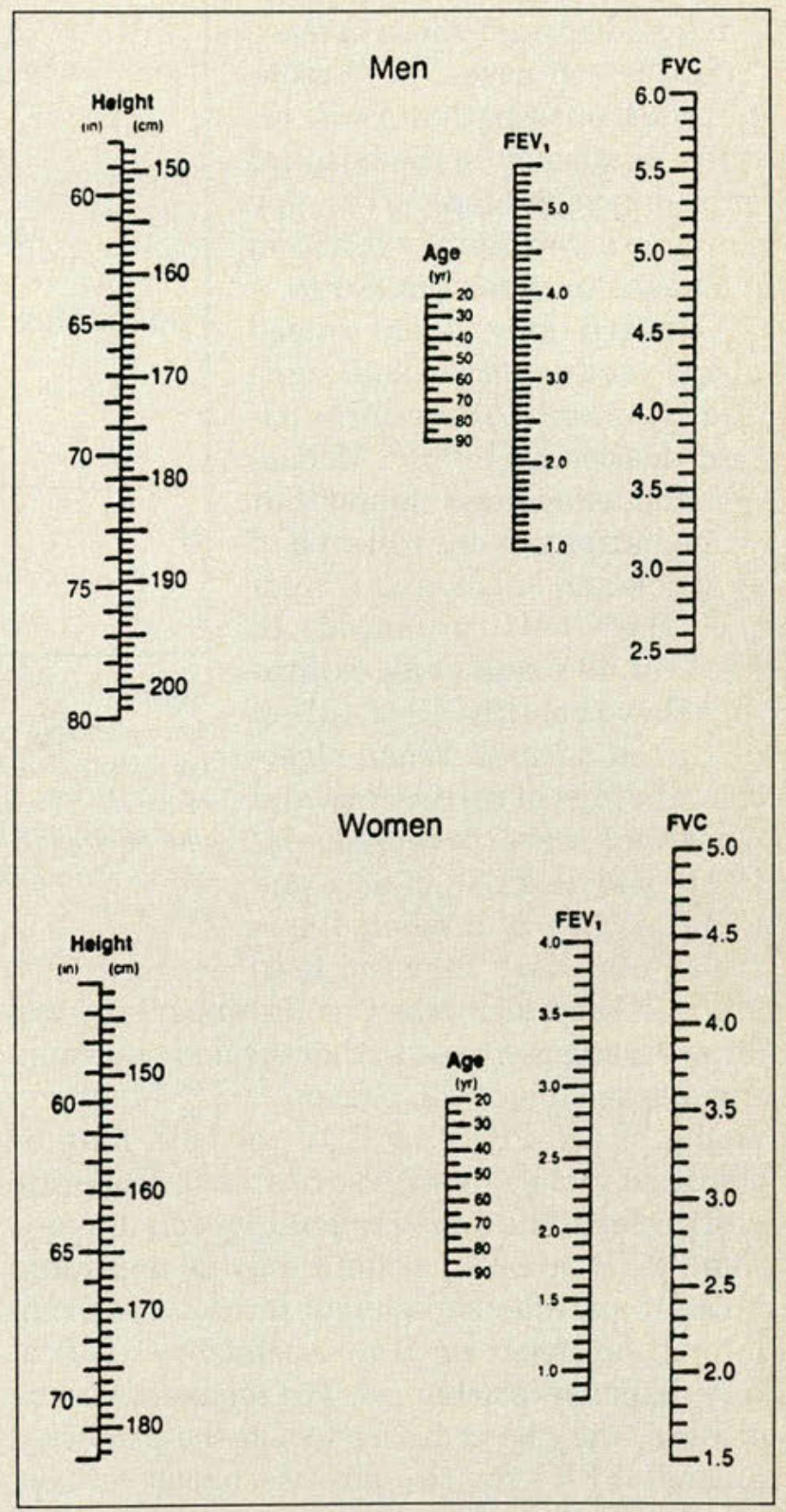

Figure 1. Nomograms for prediction of normal forced vital capacity (FVC) and forced expiratory volume in 1 second $\left(F E V_{1}\right)$ in adult men and women. (Reprinted by permission from Morris JF: Spirometry in the evaluation of pulmonary function. West J Med 1976;125:110.)

chanics and arterial blood gases are often used to assess the severity of symptomatic asthma and to facilitate decisions regarding need for hospitalization or timeliness of discharge or both. Arterial blood gases generally reveal hypoxemia and hypocapnia. In severe episodes of asthma, eucapnia or hypercapnia is often found. When arterial $\mathrm{PCO}_{2}$ measures $40 \mathrm{~mm}$ $\mathrm{Hg}$ or more, the $\mathrm{FEV}_{1}$ is less than $25 \%$ of 
predicted normal value in more than $90 \%$ of cases. ${ }^{19,20}$ Essentially all such patients will require admission to the hospital or intensive, prolonged therapy to restore ventilatory function adequate to allow discharge.

Concern has been raised about relying on patient signs and symptoms to determine patient disposition. ${ }^{15,16,21,22} \mathrm{McF}$ adden and associates ${ }^{21}$ found that when patients were relieved of dyspnea and subjective wheezing, they only produced an $\mathrm{FEV}_{1}$ of $49 \%$ and peak expiratory flow rate (PEFR) of $43 \%$ of predicted normal. When objective findings of retractions and wheezing were reversed, patients had an $\mathrm{FEV}_{1}$ of $63 \%$ and PEFR of $54 \%$ of predicted nor-

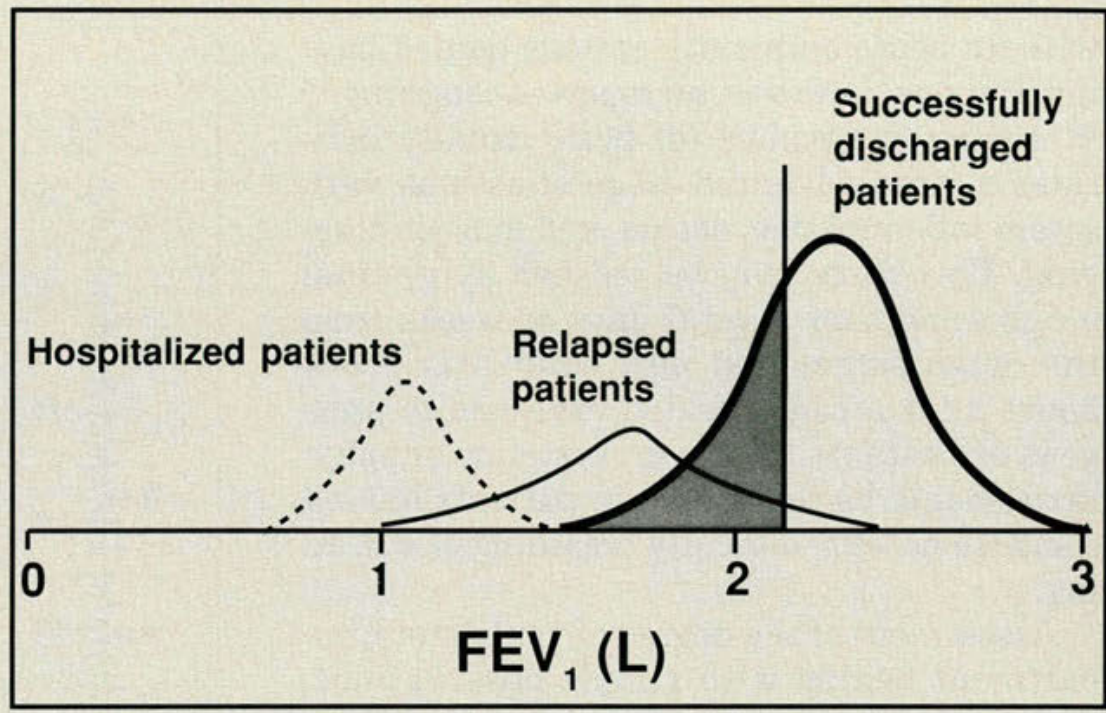

Figure 2. Estimated frequency distribution of the posttreatment forced expiratory volume in 1 second $\left(F E V_{1}\right.$ ) in three groups of patients. (Adapted by permission from Nowak and colleagues. ${ }^{19}$ ) The vertical bar represents an FEV of $2.1 \mathrm{~L}$. The shaded area represents those patients successfully discharged and having $F E V_{1}<2.1 \mathrm{~L}$. If an $F E V_{1} \leq 2.1 \mathrm{~L}$ had been used as a recommendation for admission, one third of patients would have been admitted unnecessarily. ${ }^{24}$

mal. Pulmonary function test-

ing has been advocated as an important tool for assessing response to therapy and determining disposition of the patient. ${ }^{21,23-25}$ Measurements of the PEFR or $\mathrm{FEV}_{1}$ or both may be obtained in patients who are able to cooperate and perform the forced expiratory maneuvers. The PEFR or FEV 1 or both may be measured initially and after subsequent aerosol bronchodilator treatments until a satisfactory ventilatory response is achieved. The measured value of $\mathrm{FEV}_{1}$ may be compared with the predicted normal $\mathrm{FEV}_{1}$ for the patient based on sex, height, and age (Fig 1).

Pretreatment $\mathrm{FEV}_{1}$ or PEFR values have not been shown to be accurate in predicting patient response to therapy. ${ }^{16,23,26-28}$ Also, proposed clinical index scoring systems ${ }^{14,29}$ based on presenting signs and symptoms have not been found accurate in predicting patient outcome. ${ }^{16,30,31}$ Several authors have suggested that decisions based on the degree of change in pulmonary function tests, after treatment, are useful ${ }^{16,23,32}$; however, their predictive accuracy has not been validated in prospective studies. Martin and coauthors ${ }^{23}$ suggested that patients having a $20 \%$ improvement in PEFR after initial therapy were unlikely to require hospitalization. An absolute improvement of $<400 \mathrm{~mL}$ in $\mathrm{FEV}_{1}$ was associated with a high relapse rate in the study by Kelsen and associates. ${ }^{16}$ Nowak and coworkers ${ }^{32}$ found that patients with a PEFR $<100 \mathrm{~L} / \mathrm{min}$ who did not demonstrate an improvement of $60 \mathrm{~L} / \mathrm{min}$ after initial therapy often required hospitalization. An $\mathrm{FEV}_{1}>2.1 \mathrm{~L}$ or PEFR $>300 \mathrm{~L} / \mathrm{min}$ has been advocated as a criterion for discharge. ${ }^{19,24,32}$ These values correspond to approximately $60 \%$ of predicted normal values for the average adult man. However, clinical decisions based solely on pulmonary function values at disposition will not accurately identify all patients who can be discharged successfully (Fig 2).

Worthington and Ahuju ${ }^{26}$ found that $72 \%$ of the admissions would have been unnecessary if all patients unable to achieve a $\mathrm{FEV}_{1}$ $\geq 2.1 \mathrm{~L} / \mathrm{min}$ were admitted. They propose that patients with a final $\mathrm{FEV}_{1}>2.4 \mathrm{~L} / \mathrm{min}$ can be discharged successfully with a high degree of confidence; however, this value would have identified only $41 \%$ of their patients who were discharged without relapse. Another complicating factor is that older asthmatic patients may have chronic obstructive airway disease 
affecting their ventilation status. Use of $\mathrm{FEV}_{1}$ or PEFR values for these patients necessitates knowledge of their normal asymptomatic values if the physician is to correctly evaluate the patient's responsiveness to therapy.

Pulmonary function testing is especially useful in the evaluation of high risk patients. Those who are currently taking or who have recently received corticosteroids, patients treated on an outpatient basis within 10 days, those with repeated previous hospitalizations, or patients with a history of mechanically assisted ventilation for status asthmaticus should demonstrate adequate $\mathrm{FEV}_{1}$ or PEFR function before discharge.

This article has discussed the pathophysiologic aspects of asthma and reviewed various recommendations for assessment of the acute attack. Part 2 will provide an overview of current therapy for this serious health problem.

\section{References}

1. Robin ED: Death from bronchial asthma. Chest 1989;93:614-618. 2. Sly RM: Morbidity from asthma 1979-1984. J Allergy Clin Immunol 1988;82:705-717.

3. Nelson RP, Lockey RF: Current treatment for patients with severe asthma. J Respir Dis 1988;9:29-40.

4. Jackson RT, Beaglehole R, Rea $\mathrm{HH}$, et al: Mortality from asthma: A new epidemic in New Zealand. Br Med $J$ 1982; 285:771-773.

5. Szefler SJ, Toogood JH, Spector SL, et al: A report from the Workshop on Pharmacology: Corticosteroids. J Allergy Clin Immunol 1987;80:441-442.

6. Booij-Noord H, Orie NGM, DeVries K: Immediate and late bronchial obstructive reactions to inhalation of house dust and protective effects of disodium cromoglycate and prednisolone. $J$ Allergy Clin Immunol 1971;48:344-354.

7. Pepys K, Hutchcroft BJ: Bronchial provocation tests in etiologic diagnosis and analysis of asthma. Am Rev Respir Dis 1975;112:829-859.

8. Kaliner MA: Late phase reactions in asthma. $N$ Engl Reg Allergy Proc 1986;7:236-240.

9. Berman BA: Chronic asthma. Developing the treatment plan. $J$ Allerg Clin Immunol 1982;70:170-177.

10. Dutoit JZ, Salome CM, Woolcock AJ: Inhaled corticosteroids reduce the severity of bronchial hyperresponsiveness in asthma but oral theophylline does not. Am Rev Respir Dis 1987;136:1174-1178.

11. Chung KF: Role of inflammation in hyperactivity of the airways in asthma. Thorax 1986;41:657-662.
12. Cockcroft DW: Airway hyperresponsiveness: Therapeutic implications. Ann Allergy 1987;59:405-414.

13. Josephson EB, Goetting MG: Asthmatic cardiac arrest: An indication for empiric bilateral tube thoracostomies, poster presentation, Nineteenth Annual Meeting of the Society of Academic Emergency Medicine. Ann Emerg Med 1989;4:457.

14. Fischl MA, Pitchenick A, Gardner LB: An index predicting relapse and need for hospitalization in patients with acute bronchial asthma. $N$ Engl $J$ Med 1981;305:466-470.

15. McFadden ER: Clinical physiologic correlates in asthma. $J$ Allerg Clin Immunol 1986;77:1-5.

16. Kelsen SG, Kelsen DP, Fleegler BF, et al: Emergency room assessment and treatment of patients with acute asthma. Am $J$ Med 1978;64:622-628.

17. Brenner BE, Abraham E, Simon RR: Position and diaphoresis in acute asthma. Am J Med 1983;74:1005-1009.

18. Weinberger SE: Principles of Pulmonary Medicine. Philadelphia, Pa, WB Saunders Co, 1986, p 221.

19. Nowak RM, Tomlanovich MC, Sarkar DD, et al: Arterial blood gases and pulmonary function testing in acute bronchial asthma. JAMA 1983;249:2043-2046.

20. Martin TG, Elenbaas RM, Pingleton SH: Use of peak expiratory flow rates to eliminate unnecessary arterial blood gases in acute asthma. Ann Emerg Med 1982;11:70-73.

21. McFadden ER, Kiser R, Degroot WJ: Acute bronchial asthma: Relations between a clinical and physiologic manifestations. N Engl J Med 1973;288:221-225.

22. Centor RM, Yarbrough B, Wood JP: Inability to predict relapse in acute asthma. Med Intell 1984;310:577-580.

23. Martin TG, Elenbaas RM, Pingleton SH, et al: Failure of peak expiratory flow rate to predict hospital admission in acute asthma. Ann Emerg Med 1982;11:466-470.

24. Verbeek PR, Chapman KR: Asthma: Whom to send home, when to hospitalize. $J$ Respir Dis 1986;7:15-31.

25. Franklin PK: Review of acute severe asthma. West $J$ Med 1989;150:522-556.

26. Worthington JR, Ahuju J: The value of pulmonary function tests in the management of acute asthma. Can Med Assoc $J$ 1989;140:153-156.

27. Fiel SB, Morris SA, Glanz M, et al: Efficacy of short-term corticosteroid therapy in outpatient treatment of acute bronchial asthma. Am J Med 1983;75:259-262.

28. Ownby DR, Abarzua J, Anderson JA: Attempting to predict hospital admission in acute asthma. Am J Dis Child 1984;138:1062-1066.

29. Wood DW, Downes JJ, Lecks HJ: A clinical scoring system for diagnosis of respiratory failure. Am J Dis Child 1972;123:227228.

30. Rose CC, Murphy JG, Schwartz JS: Performance of an index predicting the response of patients with acute bronchial asthma to intensive emergency department treatment. $N \mathrm{Engl}$ $J$ Med 1984;310:573-577.

31. Baker MD: Pitfalls in the use of clinical asthma scoring. Am J Dis Child 1988;142:183-185.

32. Nowak RM, Pensler MI, Sarkar DD, et al: Comparison of peak expiratory flow and $\mathrm{FEV}_{1}$ admission criteria for acute bronchial asthma. Ann Emerg Med 1982;11:64-69. 